\title{
Article \\ Effect of the Carrier on the Coprecipitation of Curcumin through Supercritical-Assisted Atomization
}

\author{
Iolanda De Marco ${ }^{1,2, *(D)}$ and Paola Franco ${ }^{1}$ \\ 1 Department of Industrial Engineering, University of Salerno, Via Giovanni Paolo II, \\ 13284084 Fisciano, SA, Italy; pfranco@unisa.it \\ 2 Research Centre for Biomaterials BIONAM, University of Salerno, Via Giovanni Paolo II, \\ 13284084 Fisciano, SA, Italy \\ * Correspondence: idemarco@unisa.it
}

Citation: De Marco, I.; Franco, P.

Effect of the Carrier on the

Coprecipitation of Curcumin through Supercritical-Assisted Atomization.

ChemEngineering 2021, 5, 59.

https://doi.org/10.3390/

chemengineering5030059

Academic Editors: Alírio

E. Rodrigues and Andrew S. Paluch

Received: 28 July 2021

Accepted: 2 September 2021

Published: 8 September 2021

Publisher's Note: MDPI stays neutral with regard to jurisdictional claims in published maps and institutional affiliations.

Copyright: (c) 2021 by the authors. Licensee MDPI, Basel, Switzerland. This article is an open access article distributed under the terms and conditions of the Creative Commons Attribution (CC BY) license (https:// creativecommons.org/licenses/by/ $4.0 /)$.

\begin{abstract}
In this paper, composite systems containing curcumin (CUR) were prepared through supercritical-assisted atomization (SAA), using different carriers. Curcumin is particularly interesting in the pharmaceutical and nutraceutical fields for its antioxidant, antitumoral, and anti-inflammatory properties. However, its therapeutic effect on human health is restricted by its poor water solubility and low dissolution rate, limiting its absorption after its oral administration. To increase the dissolution rate and then the bioavailability of the active compound, CUR was coprecipitated with polymeric, i.e., polyvinylpyrrolidone (PVP) and dextran (DXT), and not polymeric, i.e., hydroxypropyl- $\beta$ cyclodextrin (HP- $\beta-\mathrm{CD})$, carriers. The effects of some operating parameters, namely the concentration of solutes in solution and the active compound/carrier ratio, on the morphology and the particle size distribution of the powders were investigated. Submicrometric particles were produced with all the carriers. Under the best operating conditions, the mean diameters \pm standard deviation were equal to $0.69 \pm 0.20 \mu \mathrm{m}, 0.40 \pm 0.13 \mu \mathrm{m}$, and $0.81 \pm 0.25 \mu \mathrm{m}$ for PVP/CUR, DXT/CUR, and HP- $\beta$-CD/CUR, respectively. CUR dissolution rates from coprecipitated particles were significantly increased in the case of all the carriers. Therefore, the results are exciting from a pharmaceutical and nutraceutical point of view, to produce supplements containing curcumin, but assuring a high dissolution rate and bioavailability and, consequently, a more effective therapeutic effect.
\end{abstract}

Keywords: SAA coprecipitation; bioavailability; supercritical carbon dioxide; micrometric particles

\section{Introduction}

Curcumin (CUR) is a polyphenol of plant origin and is the main component of turmeric (Curcuma longa), used in traditional Asian medicine to treat multiple health problems. The scientific community's interest in CUR is linked to its anti-inflammatory, antioxidant, anticarcinogenic, and neuroprotective properties [1,2]. Some studies have shown the beneficial effects of CUR against viral infections of the respiratory tract [3]. In 2013, Barnard and Kumaki reviewed efficacious anti-severe acute respiratory syndrome coronavirus (SARS-CoV) therapies [4]; among various antiviral agents, CUR is listed as one of the natural products that inhibit SARS-CoV. As is well known to all, the gravity of the recent pandemic has heavily directed the interest of the world scientific community in the search for treatments and vaccines for the treatment of Coronavirus-2019 (COVID-19) disease, caused by SARS-CoV-2.

Soni et al. identified CUR as a potential candidate in the therapeutic regimen. The authors highlighted that CUR could hinder the cell entry and the replication of SARS-CoV-2, and prevent and repair damage associated with COVID-19 [5]. Moreover, Zahedipour et al. suggested that CUR can reverse the pulmonary edema and fibrosis-associated pathways in COVID-19 infection, inhibiting the entry of the virus into the cell, the encapsulation of the virus, and the modulation of various cellular signaling pathways [6]. 
One of the main limitations in CUR use is its practically insolubility in water $(0.1 \mathrm{mg} / \mathrm{mL})$, which induces a low dissolution rate and poor bioavailability. Increases in bioavailability and in the consequent therapeutic efficiency have been achieved considering CUR-loaded nanocarriers [7]. Indeed, it has been observed by Saber-Moghaddam et al. that when CUR oral nano-formulations are administered to hospitalized patients with mild-moderate COVID-19, patients' recovery time is significantly improved [8]. CUR has been charged through different techniques into various carriers, such as polyvinylpyrrolidone (PVP) [9], polylactic acid (PLA) [10], polycaprolactone (PCL) [11], and chitosan [12], obtaining different formulations and different dissolution profiles.

Supercritical carbon dioxide $\left(\mathrm{scCO}_{2}\right)$-based processes have been frequently used to obtain particles with improved characteristics in terms of the amplitude of particle size distribution and solvent residue [13-16]. Indeed, $\mathrm{scCO}_{2}$ possesses low critical values and properties intermediate between liquids and gases [17-19]. Micronization techniques based on the use of $\mathrm{scCO}_{2}$ are also commonly employed to coprecipitate the active principle of interest with a water-soluble polymer [20-22]. In this way, it is possible to increase the dissolution rate of the active pharmaceutical ingredient (API) while protecting it from external agents such as light and oxygen.

Among the different techniques, supercritical antisolvent precipitation (SAS) and supercritical-assisted atomization (SAA) have been frequently and efficiently used to obtain coprecipitated microparticles constituted by a polymeric matrix in which the API is dispersed [23-28]. The role that $\mathrm{scCO}_{2}$ has played in the two processes is conceptually different. In the first case, the organic solvent and $\mathrm{CO}_{2}$ are miscible under the process conditions, while the solutes to be micronized are immiscible in the $\mathrm{scCO}_{2}$-solvent mixture; the solute/solutes precipitate in the form of microparticles or nanoparticles because of the antisolvent effect. Concerning the $\mathrm{SAA}$ process, $\mathrm{scCO}_{2}$ solubilizes in the liquid solution up to a value close to the saturation one. The solution is then atomized through a nozzle in a near-atmospheric-pressure vessel with the formation of microdroplets. The microparticles are obtained from the microdroplets because of the solvent evaporation by warm nitrogen.

From an analysis of the literature related to the coprecipitation of curcumin by SAS and SAA, it appears that various papers have been published by coprecipitating curcumin by SAS [21,29-31]. In contrast, a single article concerned the coprecipitation of CUR by SAA [32]. In that paper, polyvinylpyrrolidone (PVP) was used as the polymeric carrier. The effect of CUR/PVP weight ratios was investigated, fixing the operating conditions at $80^{\circ} \mathrm{C}$ and $9.9 \mathrm{MPa}$ in the saturator and $80^{\circ} \mathrm{C}$ and $0.15 \mathrm{MPa}$ in the precipitator. The authors demonstrated that, in correspondence with the optimized operating conditions (1/8 ratio), the dissolution rate of CUR contained in SAA-coprecipitated powders was 4.5 times faster than the one of CUR in the physical mixture [32].

It is commonly recognized by the scientific community that the API dissolution rate can be modulated by appropriately choosing the polymeric carrier, regardless of the selected process conditions. Polymers such as PVP $[31,33,34]$ or cyclodextrins $[33,34]$ are used to speed up the API dissolution in an aqueous medium; others, such as zein [35] or Eudragit [36], are used to obtain a controlled or prolonged drug release.

This paper aimed to evaluate the carrier's effect and optimize the operating conditions to obtain a rapid release of CUR. Therefore, the SAA coprecipitation using three hydrosoluble polymers: PVP, dextran (DXT), and hydroxypropyl- $\beta$-cyclodextrin (HP- $\beta-C D)$, has been attempted. Indeed, all three selected carriers have already been used with $\mathrm{scCO}_{2}$-based techniques to enhance the dissolution rate of the active ingredient [37-39]. PVP and DXT tend to form coprecipitated particles in the micrometric range consisting of a polymeric matrix in which the active principle is uniformly dispersed [23,40]. On the other hand, cyclodextrins form inclusion complexes because of the weak interactions (van der Waals forces and hydrogen bonds) established between the cyclodextrin and the API [41,42]. 


\section{Materials and Methods}

\subsection{Materials}

Polyvinylpyrrolidone (PVP, average molecular weight of $10 \mathrm{~kg} / \mathrm{mol}$ ), dextran from Leuconostoc mesenteroides (DEX, average molecular weight of $43 \mathrm{~kg} / \mathrm{mol}$ ), hydroxypropyl$\beta$-cyclodextrin (HP- $\beta$-CD, purity of $99.9 \%$ ), curcumin (CUR, purity $>65 \%$ ), and ethanol $(99.9 \%)$ were provided by Sigma-Aldrich (Milan, Italy). Carbon dioxide $\left(\mathrm{CO}_{2}\right.$, purity $\left.99 \%\right)$ was supplied by Morlando Group s.r.l. (Sant'Antimo, Naples, Italy), and nitrogen $\left(\mathrm{N}_{2}\right.$, purity $99.9 \%$ ) by SON (Naples, Italy).

CUR and carriers' solubilities in the solvents were measured under ambient conditions and are reported in Table 1.

Table 1. Solubility of CUR, PVP, DEX, and HP- $\beta-C D$ in ethanol/water mixtures.

\begin{tabular}{ccc}
\hline Solute & $\begin{array}{c}\text { Solvent } \\
(\boldsymbol{v} / \boldsymbol{v})\end{array}$ & $\begin{array}{c}\text { Solubility } \\
(\mathbf{m g} / \mathbf{m L})\end{array}$ \\
\hline \multirow{2}{*}{ Curcumin } & $\mathrm{EtOH} / \mathrm{H}_{2} \mathrm{O} 70 / 30$ & 5 \\
& $\mathrm{EtOH} / \mathrm{H}_{2} \mathrm{O} 30 / 70$ & 0.8 \\
$\mathrm{EtOH}$ & 10 \\
\hline PVP & $\mathrm{EtOH}$ & 200 \\
\hline Dextran & $\mathrm{EtOH} / \mathrm{H}_{2} \mathrm{O} 30 / 70$ & 110 \\
\hline $\mathrm{HP}-\beta-\mathrm{CD}$ & $\mathrm{EtOH} / \mathrm{H}_{2} \mathrm{O} 70 / 30$ & 120 \\
\hline
\end{tabular}

\subsection{SAA Apparatus and Procedure}

The self-made SAA bench-scale apparatus is schematically represented in Figure 1.

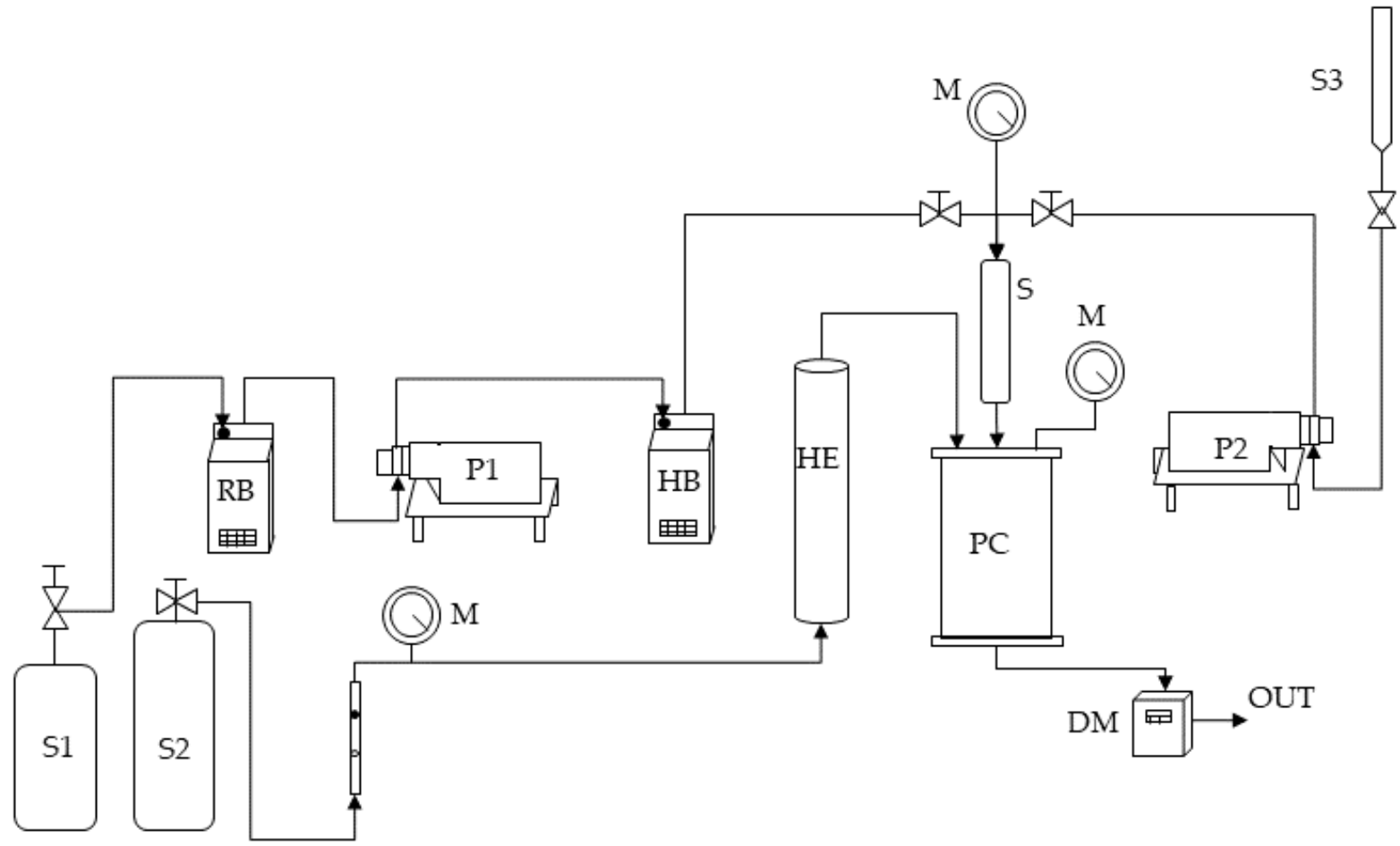

Figure 1. A sketch of the SAA laboratory plant. S1, S2, and $\mathrm{S} 3: \mathrm{CO}_{2}$ supply, nitrogen supply, and liquid solution supply; P1 and P2: pumps; RB: refrigerating bath; HB: heating bath; M: manometer; HE: heat exchanger; S: saturator; PC: precipitation chamber; DM: dry test meter.

Briefly, the high-pressure pump P1 delivers the $\mathrm{CO}_{2}$ (stored in the tank S1) to the saturator $\mathrm{S}$. The carbon dioxide before being pumped is cooled in a refrigerating bath $\mathrm{RB}$ 
to avoid pump cavitation. Furthermore, before reaching the saturator, it is pre-heated in HB. The saturator is a high-pressure vessel $\left(25 \mathrm{~cm}^{3}\right.$ internal volume $)$ in which $5 \mathrm{~mm}$ perforated Berl saddles are placed to favor optimal contact between the liquid phase and the supercritical phase and allow the achievement of thermodynamic equilibrium. The second high-pressure pump (P2) permits the feeding of the liquid solution (stored in the burette S3), consisting of the solutes solubilized in the liquid solvent to the saturator. The mixture constituted by the liquid solution and the $\mathrm{scCO}_{2}$ dissolved in it is sprayed from the saturator $S$ to the atmospheric-pressure precipitation chamber PC $\left(3000 \mathrm{~cm}^{3}\right.$ internal volume) through an $80 \mu \mathrm{m}$ internal-diameter stainless-steel nozzle. The liquid droplets evaporation is assured by a flow of nitrogen at $130{ }^{\circ} \mathrm{C}$ stored in a tank (S2) and heated in an electric heat exchanger (HE), which enters from another port from the top of the precipitation chamber. The temperature control in the saturator and the precipitation vessel is ensured by controllers connected with electrically thin bands, whereas the pressure is determined by a test gauge manometer $(\mathrm{M})$. The precipitated powder is collected at the bottom of the precipitation chamber on a stainless-steel filter (size of pores of around $0.1 \mu \mathrm{m})$, allowing the passage of the gaseous mixture $\mathrm{CO}_{2}$-solvent. The total quantity of delivered $\mathrm{CO}_{2}$ is measured at the exit by a dry test meter (DM).

\subsection{Characterization}

The morphology of the powders was observed using a field-emission scanning electron microscope (FESEM, mod. LEO 1525, Carl Zeiss SMT AG, Oberkochen, Germany). In the downstream sampling phase of each experiment, various powder samples were taken at different heights inside the precipitator and from the filter. Before proceeding with the analysis of the samples by microscope, they were subjected to metallization, which consisted of covering them with a very thin layer of gold-palladium to make them conductive.

The particle size distribution (PSD) was subsequently determined by image analysis using high-magnification FESEM images. In practice, approximately 1000 particles were measured for each experiment using the Sigma Scan Pro image analysis software (version 5.0, Aspire Software International Ashburn, VA, USA). The measured diameters were then implemented within the Microcal Origin software (version 8.0, Northampton, MA, USA), which allows the obtaining of the mean size and the standard deviation and the representation of the PSD through histograms.

Fourier-transform infrared (FTIR) analysis was performed to check if the material had undergone any changes downstream of the SAA process. The investigation was carried out through an FTIR spectrophotometer (Vortex 70 FT-IR, Bruker Optics, Ettlingen, Germany) in a scan wavenumber range of $4000-400 \mathrm{~cm}^{-1}$ at a resolution of $0.5 \mathrm{~cm}^{-1}$ as the mean of 16 measurements. The samples to be examined were prepared in the form of tablets using potassium bromide as a support (not detected by the instrument in the absorption spectrum of the compound under examination). The two materials were mixed (about $100 \mathrm{mg}$ of $\mathrm{KBr}$ for each sample $\mathrm{mg}$ ) using a mortar; the tablets were prepared by compressing the solid mixture formed in a hydraulic press. Analyses were performed in triplicates.

The samples were subjected to thermal analysis with the aid of a differential scanning calorimeter (DSC, mod. TC11, Mettler-Toledo, Inc., Columbus, OH, USA) using the Mettler STARe system. The sample to be analyzed was a few milligrams $(5 \pm 0.5 \mathrm{mg})$ to avoid establishing a thermal profile within the sample and to prevent any melt from escaping from the capsule. The DSC analyses were carried out by heating the prepared samples from 25 to $350{ }^{\circ} \mathrm{C}$, with a speed of $10{ }^{\circ} \mathrm{C} / \mathrm{min}$ under a nitrogen gas flux equal to $100 \mathrm{~mL} / \mathrm{min}$. Analyses were performed in triplicate. The effective presence of the active ingredient loaded into the carrier was obtained using a UV/vis spectrophotometer (Cary 50, Varian, Palo Alto, CA, USA). The instrument measured the turbidity variation of the reading medium at a wavelength of $425 \mathrm{~nm}$ (characteristic of CUR). A fixed amount of sample, equal to $5 \mathrm{mg}$, was dissolved in $5 \mathrm{~mL}$ of ethanol and analyzed, in order to calculate the CUR concentration in the samples and estimate the encapsulation efficiency (EE), expressed as the ratio between the real measured CUR content and the theoretical one. 
For the preparation of the blank test, $5 \mathrm{mg}$ of the carrier was dissolved in ethanol and the absorbance of the blank test was subtracted to the sample absorbance. In this way, the presence of the carrier in the solution did not interfere with the detection of curcumin.

Dissolution tests were performed with the same UV/vis spectrophotometer, using phosphate-buffered saline (PBS) at $\mathrm{pH} 6.8$ as the liquid medium, which simulates intestinal fluid, in agreement with the literature [43]. Samples containing an equivalent amount of CUR equal to $2 \mathrm{mg}$ were introduced into a dialysis membrane (cut-off of 12-14,000 Da), which was then placed into $300 \mathrm{~mL}$ of PBS at $\mathrm{pH} 6.8$ [44]. For the analyses, the beaker method was used. The system was incubated at $37.0 \pm 0.5^{\circ} \mathrm{C}$ (to simulate the body environment) and stirred at $150 \mathrm{rpm}$ [32]. The stirring rate was kept constant using a magnetic stirrer while keeping the magnet at the bottom of the beaker. To convert the absorbances read by the spectrophotometer into CUR concentrations, a calibration line was determined using solutions containing CUR at five different concentrations in PBS. The obtained line had the form $y=4.6797 \cdot x$ (with a correlation coefficient $R^{2}=0.9958$ ). Analyses were performed in triplicate, and the shown profiles are the average of the calculations.

\section{Results and Discussion}

Some operating conditions already optimized in previous studies $[23,32,45]$ have been fixed and are reported in Table 2.

Table 2. Fixed operating conditions. $\mathrm{P}_{\mathrm{SAT}}$ : pressure in the saturator; $\mathrm{T}_{\mathrm{SAT}}$ : temperature in the saturator; $\mathrm{T}_{\mathrm{PC}}$ : temperature in the precipitation chamber; GLR: gas-to-liquid ratio.

\begin{tabular}{cccc}
\hline Carrier & $\begin{array}{c}\mathbf{P}_{\text {SAT }} \\
(\mathbf{M P a})\end{array}$ & $\begin{array}{c}\mathbf{T}_{\text {SAT }} \\
\left({ }^{\circ} \mathbf{C}\right)\end{array}$ & $\begin{array}{c}\mathbf{T}_{\mathbf{P C}} \\
\left({ }^{\circ} \mathbf{C}\right)\end{array}$ \\
\hline PVP & 8.0 & 80 & 80 \\
\hline Dextran & 9.2 & 85 & 100 \\
\hline HP- $\beta-C D$ & 9.0 & 80 & 100 \\
\hline
\end{tabular}

According to the literature, for all the carriers investigated, the GLR (gas-to-liquid ratio) was set at 1.8, which is an optimal value for SAA micronization [46]. This value corresponds to a $\mathrm{CO}_{2}$ mass flow rate equal to $9 \mathrm{~g} / \mathrm{min}$ and a liquid solvent flow rate equal to $5 \mathrm{~g} / \mathrm{min}$. The experiments were conducted by varying the carrier/CUR ratio $(w / w)$ and the total concentration of the liquid solution. The tested operating conditions are reported in Table 3, with the obtained morphology, the mean diameter (m.d.), and the standard deviation (s.d.) of the produced particles.

Table 3. A summary of SAA experiments conducted. SMP: sub-microparticles; cSMP: cohesive sub-microparticles; $\mathrm{C}_{\text {tot }}$ : total concentration of solutes; m.d.: mean diameter; s.d.: standard deviation.

\begin{tabular}{|c|c|c|c|c|c|}
\hline$\#$ & Carrier & Carrier/CUR $(w / w)$ & $\begin{array}{c}\mathrm{C}_{\text {tot }} \\
(\mathrm{mg} / \mathrm{mL})\end{array}$ & Morphology & $\begin{array}{c}\text { m.d. } \pm \text { s.d. } \\
{[\mu \mathrm{m}]}\end{array}$ \\
\hline 1 & \multirow{3}{*}{ PVP } & $10 / 1$ & \multirow{3}{*}{10} & SMP & $0.69 \pm 0.20$ \\
\hline 2 & & $6 / 1$ & & Slightly cSMP & $0.44 \pm 0.15$ \\
\hline 3 & & $3 / 1$ & & cSMP & $0.43 \pm 0.14$ \\
\hline 4 & \multirow[b]{2}{*}{ DEX } & $10 / 1$ & \multirow{2}{*}{5} & SMP & $0.40 \pm 0.13$ \\
\hline 5 & & $6 / 1$ & & cSMP & $0.45 \pm 0.15$ \\
\hline 6 & & $10 / 1$ & 20 & SMP & $0.84 \pm 0.24$ \\
\hline 7 & \multirow{3}{*}{$H P-\beta-C D$} & \multirow{3}{*}{$6 / 1$} & 5 & SMP & $0.51 \pm 0.16$ \\
\hline 8 & & & 10 & cSMP & $0.73 \pm 0.23$ \\
\hline 9 & & & 20 & SMP & $0.85 \pm 0.26$ \\
\hline 10 & & $3 / 1$ & 20 & SMP & $0.81 \pm 0.25$ \\
\hline
\end{tabular}




\subsection{PVP/CUR System}

The first set of experiments (\#1-3) was performed at a fixed concentration of the liquid solution equal to $10 \mathrm{mg} / \mathrm{mL}$, with the PVP/CUR $w / w$ ratio varying from $10 / 1$ to 3/1. The FESEM images of the particles are reported in Figure 2a-c, whereas the particles size distributions (PSDs) are compared in Figure 2d. From a morphological point of view, it is possible to observe that more collapsed particles were obtained with the decrease in the PVP/CUR ratio. The collapse of microparticles may be due to the fragility of the solid structure formed. It can be correlated to CUR presence as the PVP particles alone formed by SAA did not show this characteristic [25]. The collapse of particles was particularly evident as R increased, confirming its correlation with the CUR content's increase.

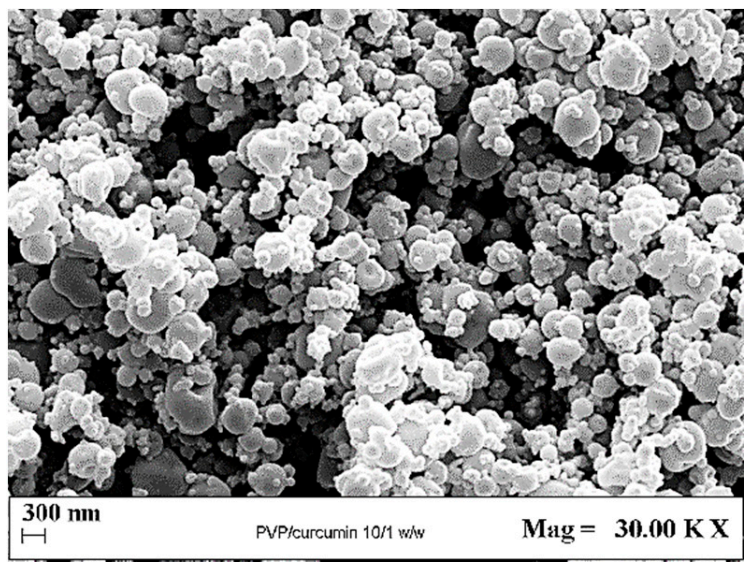

(a)

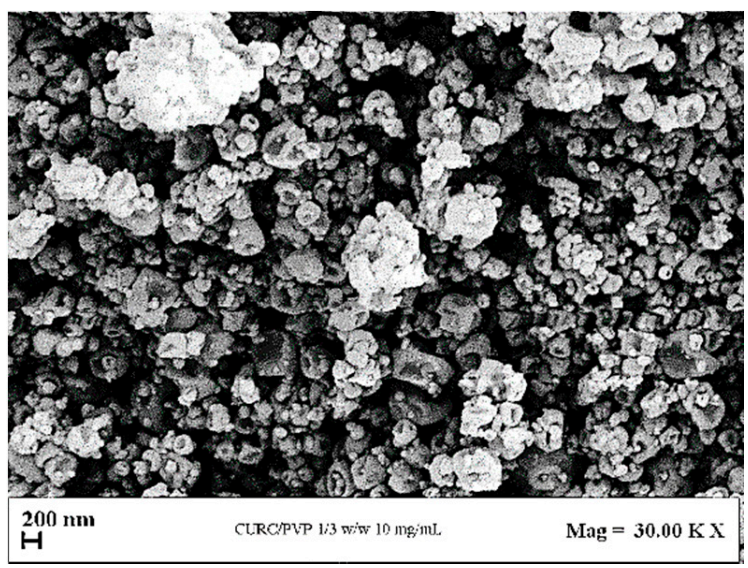

(c)

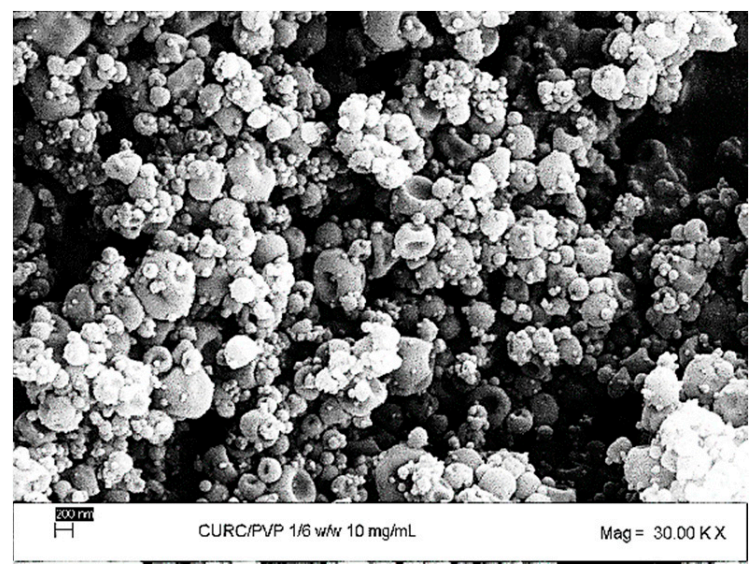

(b)

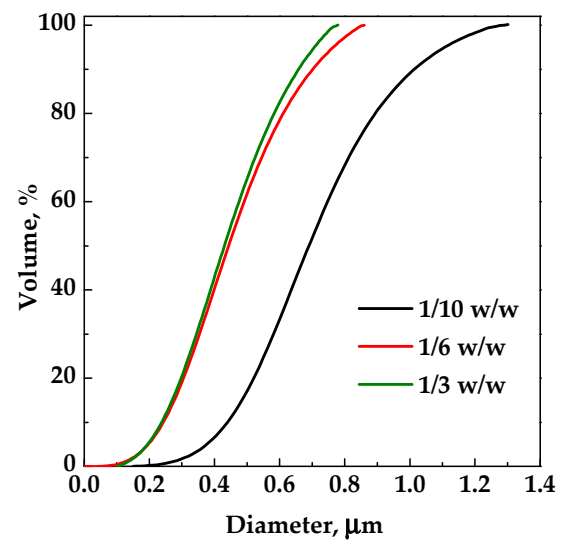

(d)

Figure 2. PVP/CUR particles produced by SAA from EtOH at $10 \mathrm{mg} / \mathrm{mL}$. Effect of the carrier/API ratio: (a) 10/1 w/w; (b) $6 / 1 w / w$; (c) $3 / 1 w / w$; (d) particle size distribution of the powders obtained under different conditions.

By comparing the volumetric cumulative PSDs (reported in Figure 2d), it is possible to observe that, increasing the PVP/CUR ratio from $3 / 1$ to $6 / 1$, the mean diameter was not affected by the increase in the polymer/active principle ratio; at a ratio equal to $10 / 1$, the average diameter increased. 


\subsection{DEX/CUR System}

Tests on the dextran/curcumin system were performed by decreasing the DXT/CUR ratio from $10 / 1$ to $6 / 1 w / w$. This mass ratio was not further reduced, because of the limited solubility of curcumin in the solvent mixture suitable for dextran. Moreover, considering the reduced value of solubility, the total concentration of the solutes in the liquid mixture was fixed at $5 \mathrm{mg} / \mathrm{mL}$. From the FESEM images reported in Figure 3, it is possible to observe that sub-microparticles ware obtained in both cases. Still, in correspondence of a DXT/CUR $w / w$ ratio equal to $6 / 1$, a coalescence/cohesion between the particles can be noted. Comparing the mean diameter \pm standard deviation (reported in Table 3 for tests \#4 and \#5), we can affirm that by decreasing the dextran/curcumin mass ratio from 10/1 to $6 / 1$, the mean diameter increased and the particle distribution enlarged.

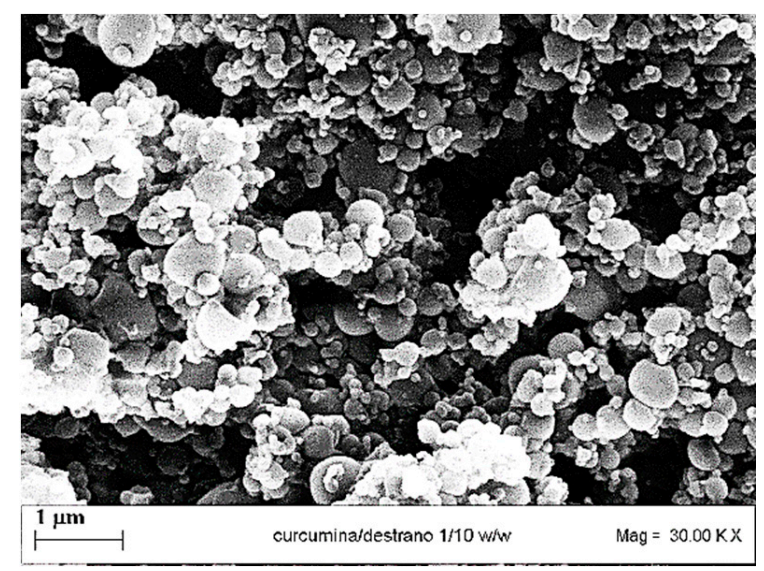

(a)

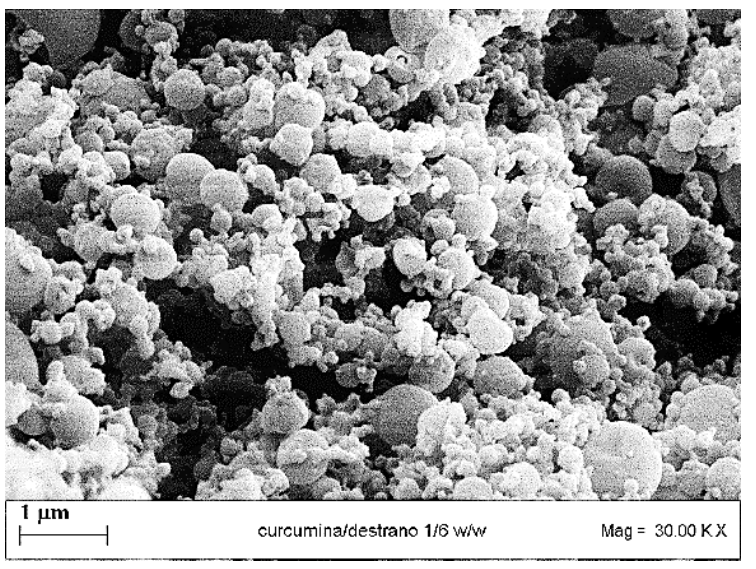

(b)

Figure 3. DXT/CUR particles produced by SAA from EtOH/ $\mathrm{H}_{2} \mathrm{O} 70 / 30$ at $5 \mathrm{mg} / \mathrm{mL}$. Effect of the API/carrier ratio: (a) $10 / 1 w / w ;(\mathbf{b}) 6 / 1 w / w$.

\section{3. $H P-\beta-C D / C U R$ System}

The HP- $\beta-C D /$ curcumin was also studied. In this case, the effect of the total concentration and of the mass ratio on the morphology and size of the particles were evaluated. The study of this system is particularly significant as cyclodextrins allow the production of composite particles with a greater quantity of loaded active principle.

\subsubsection{Effect of the Concentration of the Solution}

For this set of experiments (\#7-9), the HP- $\beta-C D / C U R$ ratio was fixed at $6 / 1 w / w$. The total concentration in the liquid solution constituted by the solutes dissolved in an $\mathrm{EtOH} / \mathrm{H}_{2} \mathrm{O} 70 / 30$ mixture was varied from 5 to $20 \mathrm{mg} / \mathrm{mL}$. In Figure 4, the FESEM images of the three different tests and the cumulative volumetric particle size distribution are reported. Regarding morphology, sub-microparticles were obtained in all the cases. In terms of mean diameter, it is possible to see (Figure $4 \mathrm{~d}$ ) that, increasing the concentration from $5 \mathrm{mg} / \mathrm{mL}$ to $20 \mathrm{mg} / \mathrm{mL}$, the average diameter increased. This behavior is commonly observed in SAA-precipitated powders as, increasing the solute concentration, the viscosity of the solution increases, and larger droplets are formed at the injector outlet, resulting in the production of larger dried particles. 


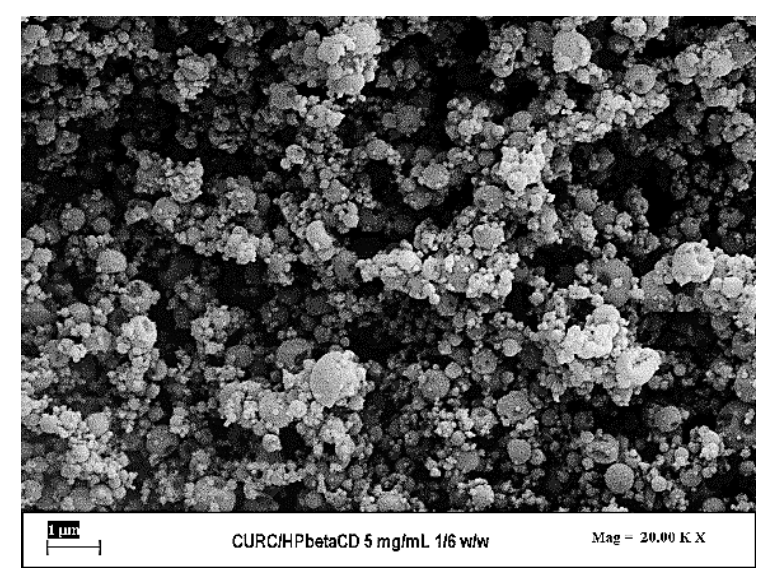

(a)

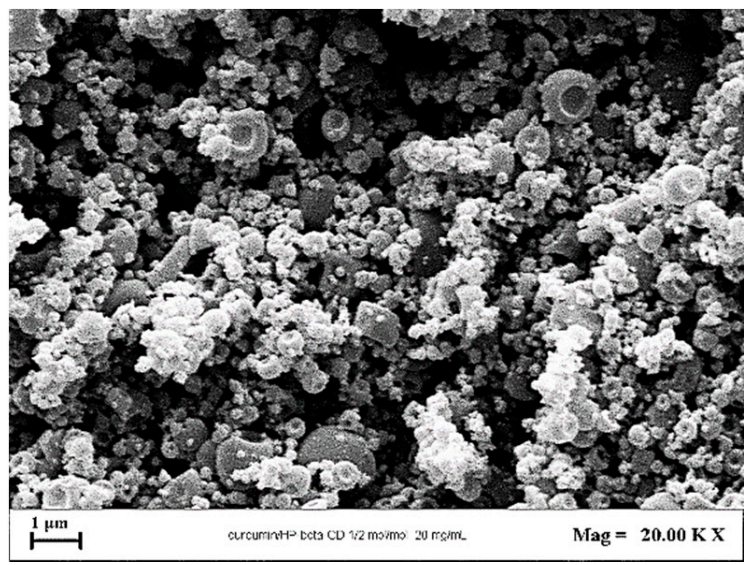

(c)

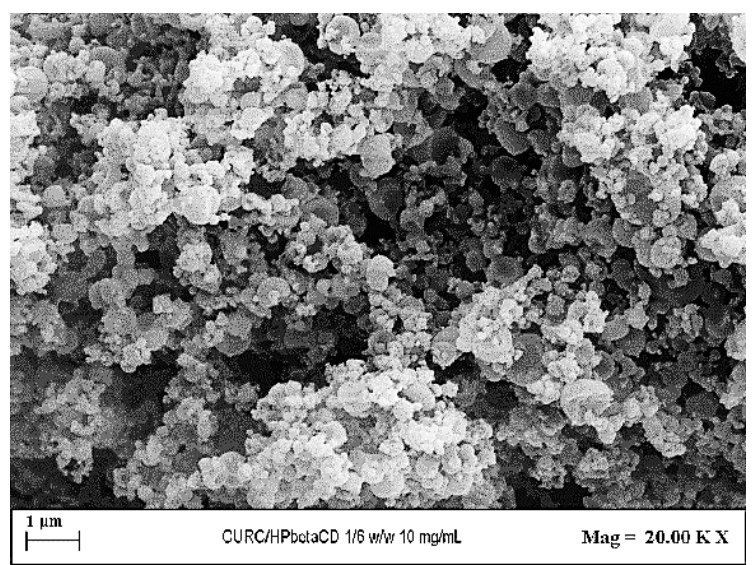

(b)

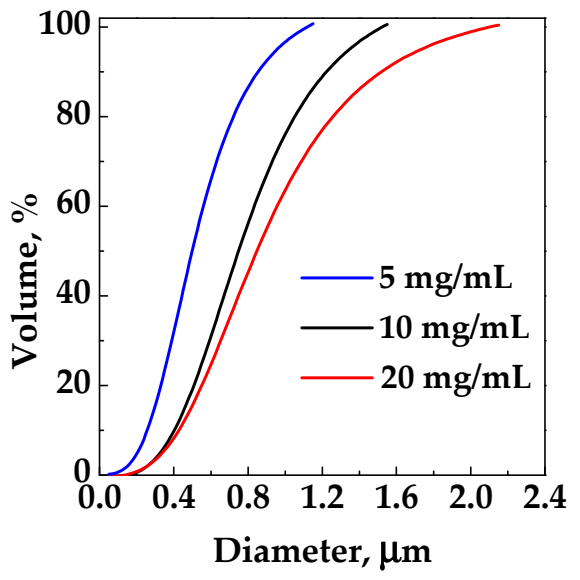

(d)

Figure 4. HP- $\beta-\mathrm{CD} / \mathrm{CUR}$ particles produced by SAA from $\mathrm{EtOH} / \mathrm{H}_{2} \mathrm{O} 70 / 30$ at $6 / 1 w / w$ ratio. Effect of total concentration in the liquid solution: (a) $5 \mathrm{mg} / \mathrm{mL}$; (b) $10 \mathrm{mg} / \mathrm{mL}$; (c) $20 \mathrm{mg} / \mathrm{mL}$; (d) particle size distribution of the powders obtained in correspondence of the different concentrations.

\subsubsection{Effect of HP- $\beta-C D / C U R$ Ratio}

For this set of experiments, the total concentration was set at $20 \mathrm{mg} / \mathrm{mL}$, and three tests were conducted by varying the HP- $\beta-\mathrm{CD} / \mathrm{CUR}$ mass ratio. In particular, the first test was carried out considering a carrier/API ratio equal to $10 / 1 w / w$; then, the ratio was gradually decreased down to $3 / 1 w / w$. In all the cases, well-defined sub-microparticles were obtained. Considering the data reported in Table 3 (tests \#6, 9, and 10), it is evident that the carrier/API ratio did not have a relevant effect on the average diameter and the particle size distribution.

\subsection{Characterization}

FT-IR spectroscopic analysis was conducted on pure curcumin and carriers and the different SAA systems to identify possible interactions at the functional group level between the active ingredient and the carrier; the spectra are reported in Figure 5. 


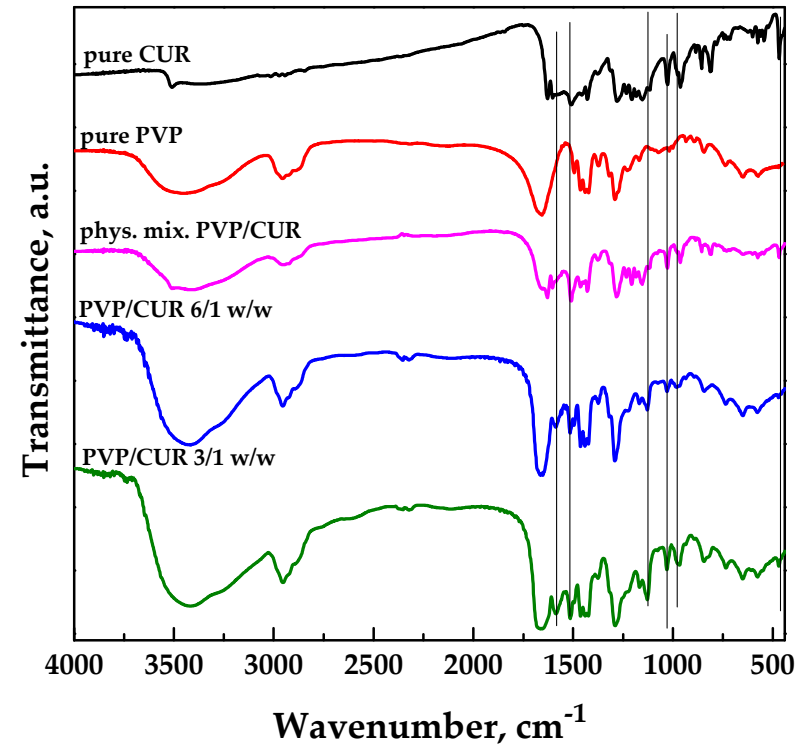

(a)

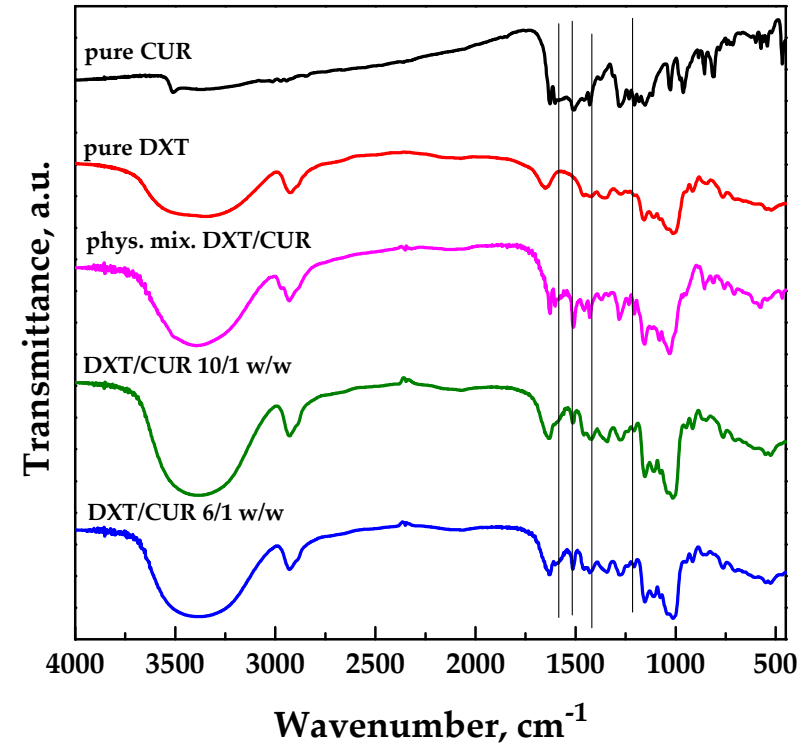

(b)

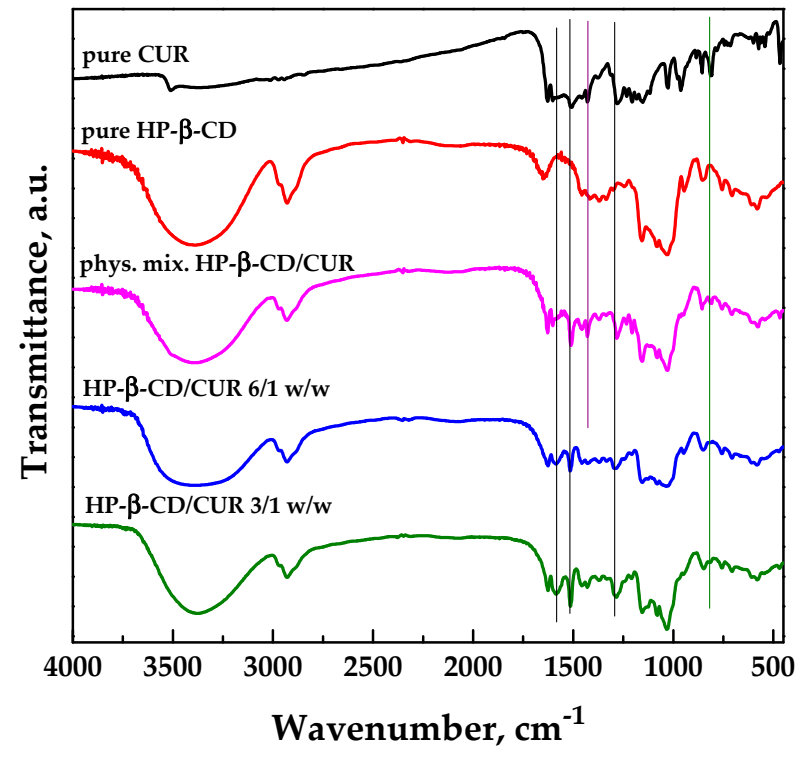

(c)

Figure 5. FT-IR spectra of unprocessed, physical mixtures and SAA processed carrier/CUR powders: (a) PVP; (b) DEX; (c) $\mathrm{HP}-\beta-\mathrm{CD}$.

The spectrum of pure curcumin showed stretching vibrations at $1628 \mathrm{~cm}^{-1}$ attributed predominantly to the overlapping stretching vibrations of alkenes $(C=C)$ and carbonyl $(\mathrm{C}=\mathrm{O})$ character. The spectrum also showed a stretching vibration at $3200-3500 \mathrm{~cm}^{-1}$ due to $\mathrm{O}-\mathrm{H}$ groups, a $\mathrm{C}=\mathrm{C}$ aromatic stretching vibration at $1427 \mathrm{~cm}^{-1}$, and a high-intensity band at $1512 \mathrm{~cm}^{-1}$ attributed to the mixed vibrations, including stretching carbonyl bond vibrations $\vee(C=O)$, in-plane bending vibrations around aliphatic $\delta C C-C, \delta C C=O$ and in-plane bending vibrations around aromatic $\delta \mathrm{CC}-\mathrm{H}$ of keto and enol configurations, and stretching vibrations around aromatic $v \mathrm{CC}$ bonds of the keto and enolic form of curcumin. Furthermore, a significant intense band at $1277 \mathrm{~cm}^{-1}$ was attributed to the bending vibration of the $v(\mathrm{C}-\mathrm{O})$ phenolic band [47]. 
The pure PVP spectrum showed a characteristic absorption band at $3469 \mathrm{~cm}^{-1}$ due to the stretching of the $-\mathrm{OH}$ group, a peak at $1653 \mathrm{~cm}^{-1}$ corresponding to the stretching of the $\mathrm{C}=\mathrm{O}$ groups, and a peak at $2875 \mathrm{~cm}^{-1}$ attributable to the stretching of the $\mathrm{C}-\mathrm{H}$ group [27]. However, there were also characteristic peaks of curcumin (black vertical lines), which confirmed its presence in the coprecipitated powders. The typical bands of PVP dominated the spectra of the physical mixture and SAA powders, as the polymer was present in more significant quantities than curcumin.

Figure $5 b$ shows the infrared spectra relating to pure CUR and pure DEX, SAA co-precipitates obtained at different carrier/CUR ratios. The spectrum of pure dextran showed a broad band at about $3500 \mathrm{~cm}^{-1}$ due to $\mathrm{O}-\mathrm{H}$ stretching vibrations, a band at about $2900 \mathrm{~cm}^{-1}$, which refers to $\mathrm{C}-\mathrm{H}$ stretching, and partially overlapping bands at $1200-800 \mathrm{~cm}^{-1}$, associated with C-O-C absorptions [45]. Some characteristic bands of curcumin (highlighted with black vertical lines) could be observed in the SAA samples' spectra and the physical mixture. However, a major correspondence with the polymer spectrum due to the higher amount of the latter one into the composite powders could be detected.

Figure $5 c$ shows the FT-IR spectra related to the system HP- $\beta-C D / C U R$. The spectrum of pure HP- $\beta$-CD showed two prominent absorption bands at $3414 \mathrm{~cm}^{-1}$ and $2929 \mathrm{~cm}^{-1}$ due to the stretching of the $-\mathrm{OH}$ and $\mathrm{CH}$ groups, respectively. In addition, it showed a peak at $1638 \mathrm{~cm}^{-1}$ attributable to the bending of the $\mathrm{H}-\mathrm{O}-\mathrm{H}$ group, a peak at $1157 \mathrm{~cm}^{-1}$ linked to the asymmetric stretching of the $\mathrm{C}-\mathrm{O}-\mathrm{C}$ glycosidic bridge, and two peaks corresponding to wavenumbers equal to 1082 and $1032 \mathrm{~cm}^{-1}$ due to the stretching of groups C-C and $\mathrm{C}-\mathrm{O}$, respectively [48]. The spectra of the physical mixture and the SAA process were more similar to the cyclodextrin one; however, some characteristic bands of curcumin were visible, highlighted with black vertical lines in the graph. Some typical bands of curcumin, indicated with green vertical lines, were instead observed in the spectrum of the physical mixture but not in the SAA powders, probably due to the capability of the cyclodextrin to form inclusion complexes. Indeed, the disappearance of some characteristic bands of the active compound can be attributed to its incorporation into the cyclodextrin cavity, so curcumin was "hidden" [41].

Differential scanning calorimetry analyses were conducted on pure materials and coprecipitated powders and are reported in Figure 6. Curcumin alone is crystalline; its thermogram showed the melting peak at $174{ }^{\circ} \mathrm{C}$ [32]. The pure PVP curve had only a broad endothermic peak below $100{ }^{\circ} \mathrm{C}$, linked to water loss. The coprecipitated powders showed an amorphous behavior similar to the PVP one, while the curcumin melting peak was not detected, because the drug was incorporated within the polymer. The unprocessed dextran diffractogram (as reported in Figure $6 \mathrm{~b}$ ) showed a large endothermic peak at a low temperature due to the dehydration process [23]. The coprecipitated powders' thermogram was similar to the polymer one because the coprecipitated powders were amorphous as the polymer and because the curcumin was hidden in the polymeric matrix.

The cyclodextrin had a large endothermic peak between $40^{\circ} \mathrm{C}$ and $150{ }^{\circ} \mathrm{C}$, relating to the loss of volatile compounds. This peak was also slightly visible in the thermogram related to the coprecipitated powders; however, its intensity was reduced probably because of a displacement between the water molecules into the CD cavity and the curcumin to form inclusion complexes, reaching a more stable energy state [41]. 


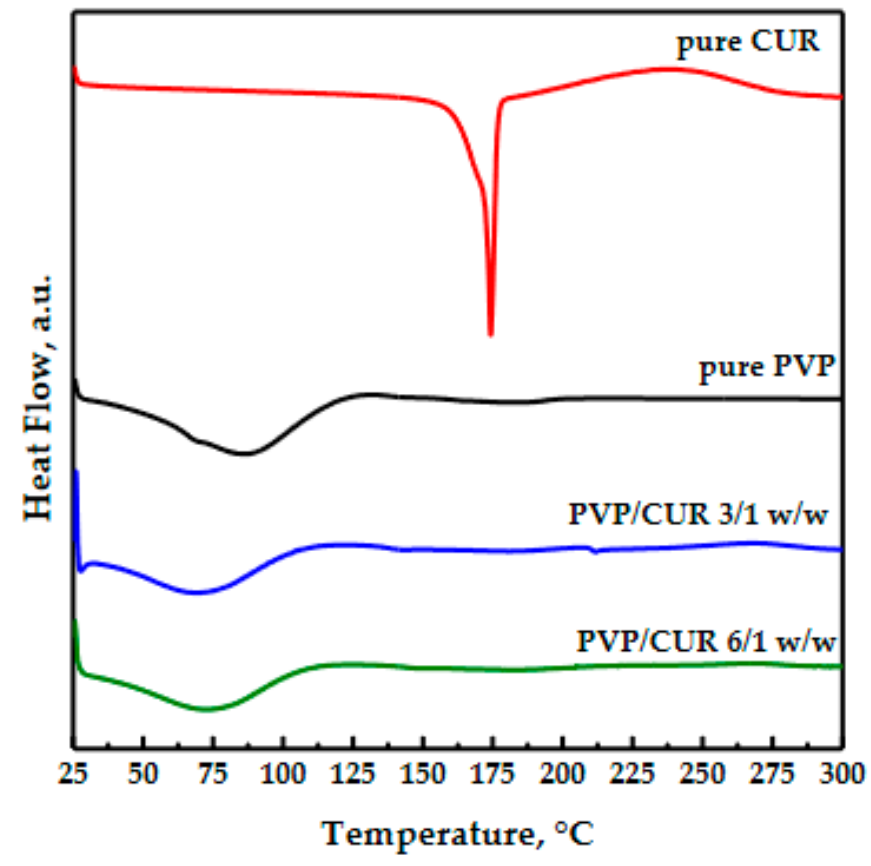

(a)

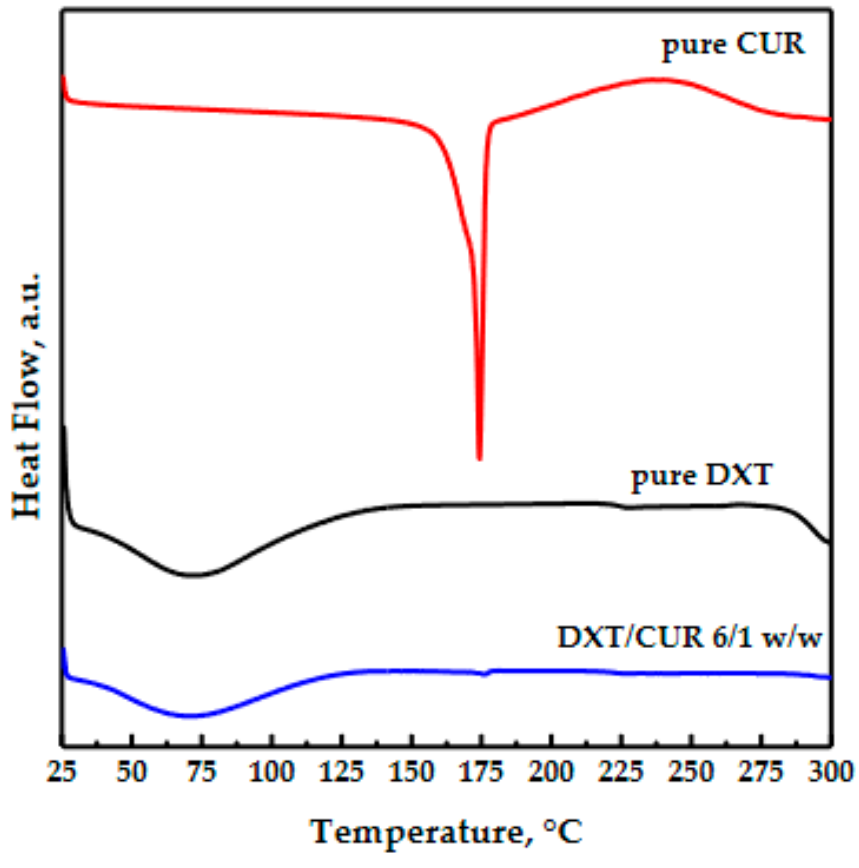

(b)

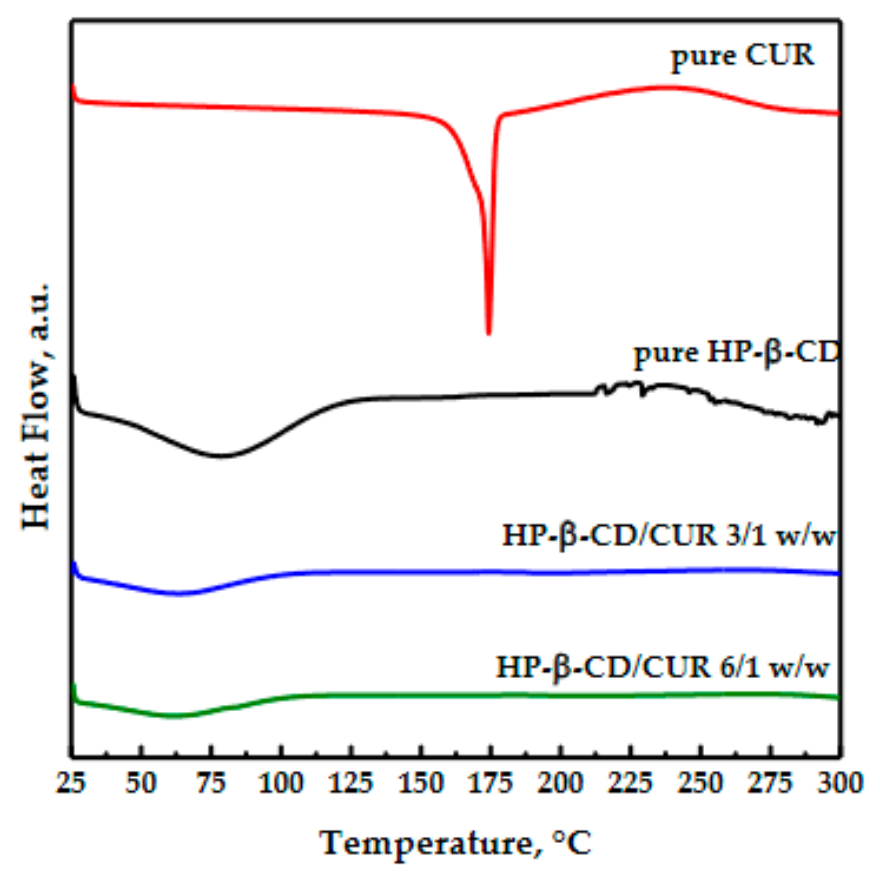

(c)

Figure 6. Diffractograms of unprocessed carriers and CUR and SAA processed carrier/CUR powders: (a) PVP; (b) DEX; (c) HP- $\beta-C D$.

Real CUR loadings were measured by UV-vis analysis to evaluate the effective amount of the active compound in the coprecipitated particles. The results reported in Table 4 together with the corresponding encapsulation efficiency showed that the encapsulation efficiency was higher than $97.8 \%$ for all the carriers and all the carrier/CUR weight ratios. 
Table 4. CUR loadings and encapsulation efficiency (EE) for the particles obtained by SAA process using the different carriers.

\begin{tabular}{ccccc}
\hline Carrier & $\begin{array}{c}\text { Carrier/CUR } \\
(\boldsymbol{w} / \boldsymbol{w})\end{array}$ & $\begin{array}{c}\text { Theoretical Loading } \\
\mathbf{( \% )}\end{array}$ & $\begin{array}{c}\text { Real Loading } \\
\mathbf{( \% )}\end{array}$ & $\begin{array}{c}\text { EE } \\
\mathbf{( \% )}\end{array}$ \\
\hline \multirow{3}{*}{ PVP } & $10 / 1$ & 9.09 & $9.07 \pm 0.21$ & 99.8 \\
& $6 / 1$ & 14.29 & $14.02 \pm 0.22$ & 98.1 \\
\multirow{2}{*}{ Dextran } & $3 / 1$ & 25.00 & $24.45 \pm 0.20$ & 97.8 \\
\hline \multirow{3}{*}{ HP- $\beta-C D$} & $10 / 1$ & 9.09 & $9.02 \pm 0.18$ & 99.2 \\
& $6 / 1$ & 14.29 & $14.20 \pm 0.20$ & 99.4 \\
\hline
\end{tabular}

The dissolution profiles reported in Figure 7 were measured on curcumin in pure form or released from different coprecipitates to highlight the influence of the various carriers on the CUR dissolution rate.

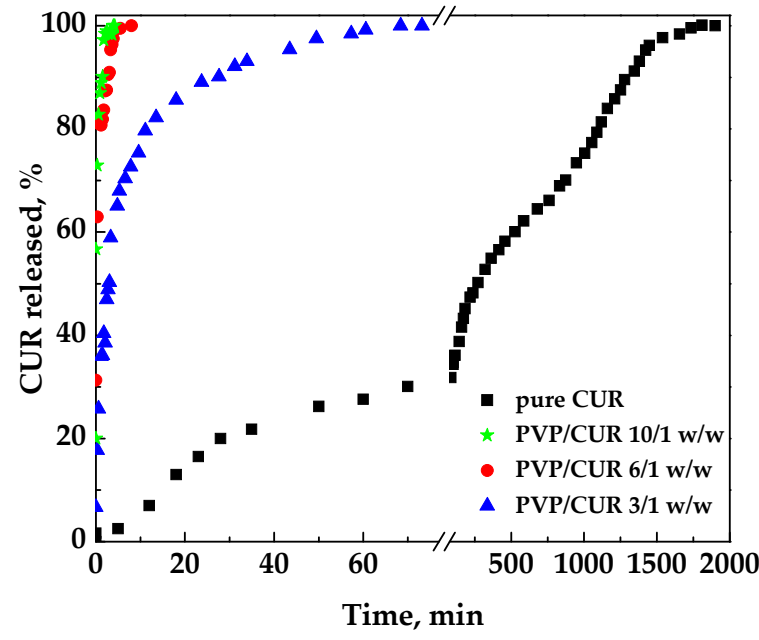

(a)

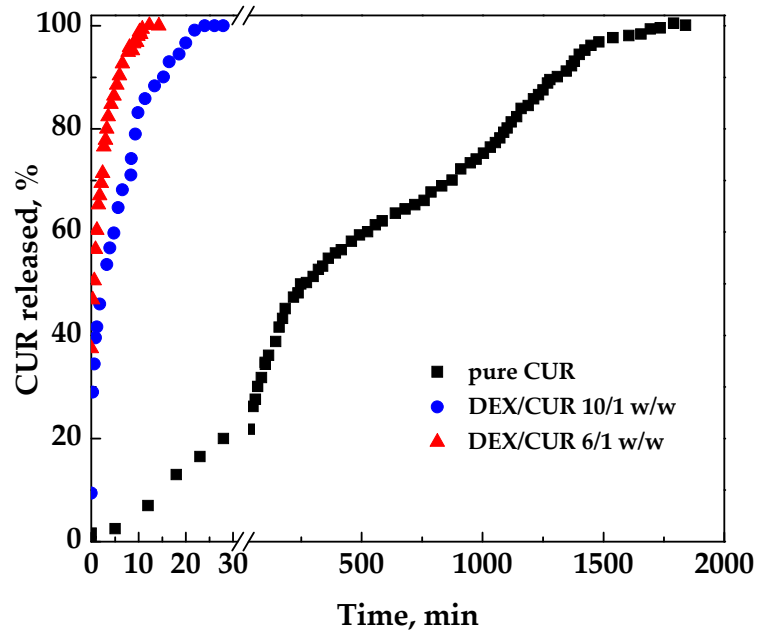

(b)

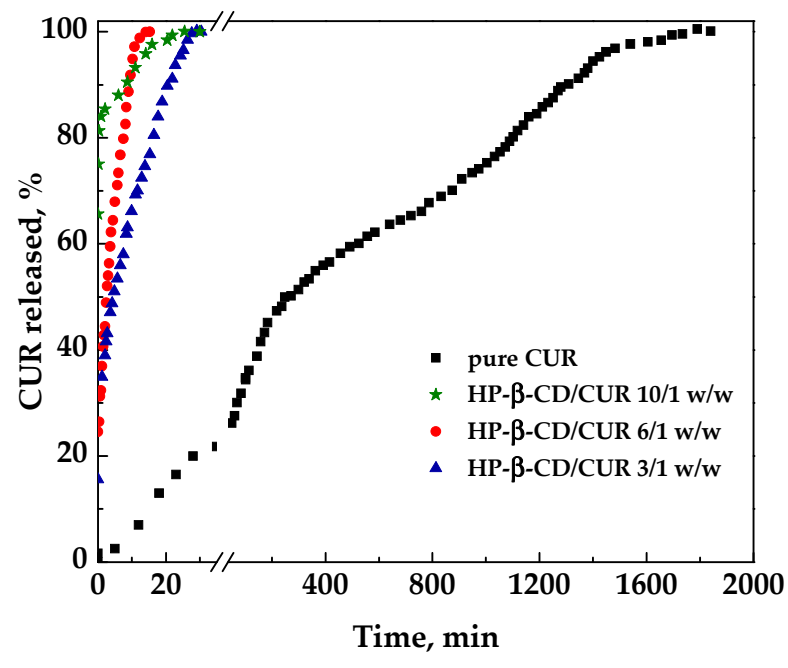

(c)

Figure 7. Dissolution profiles of CUR in PBS from powders coprecipitated with different polymeric and not polymeric carriers: (a) PVP; (b) DEX; (c) HP- $\beta-C D$. 
Pure curcumin was entirely dissolved in the liquid medium in about $31.7 \mathrm{~h}$. Considering the system PVP/CUR (Figure 7a), it is possible to observe that the time took to reach the plateau was significantly reduced with all the SAA PVP/CUR samples; specifically:

- $\quad$ curcumin was released in a few minutes from PVP/CUR 10/1 w/w particles;

- $\quad$ curcumin was released in 8 min from PVP/CURC 6/1 w/w powders;

- curcumin was released from PVP/CUR 3/1 w/w in 70 min.

It was noted that the time for the complete dissolution decreased by increasing the carrier's amount. However, from a pharmaceutical point of view, the sample 3/1 w/w was probably the best one as the amount of carrier was reduced. At the same time, the dissolution rate was faster than the one of pure curcumin, but not too much as conversely occurred with the other SAA samples.

Regarding the dextran/curcumin/dextran, the dissolution profiles of which are reported in Figure $7 \mathrm{~b}$, curcumin was released in 30 min considering the 10/1 w/w system and in about $15 \mathrm{~min}$ for the $6 / 1 \mathrm{w} / \mathrm{w}$ system.

Regarding the cyclodextrin/CUR samples, the HP- $\beta$-CD/curcumin $3 / 1 w / w$ sample showed a faster dissolution than the pure curcumin did, taking about $30 \mathrm{~min}$ for the complete dissolution. In contrast, HP- $\beta-\mathrm{CD} /$ curcumin $6 / 1 w / w$ and $10 / 1 w / w$ took about 15 min. Additionally in this case, $\mathrm{HP}-\beta-\mathrm{CD} /$ curcumin $3 / 1 w / w$ is probably the best choice from a pharmaceutical point of view.

To determine the effect of the carrier employed, it is possible to consider a comparison of the profiles of curcumin released from the different coprecipitated powders at a specific carrier/curcumin ratio. Specifically, using the same amount of carrier, namely $6 / 1 w / w$, PVP showed the fastest dissolution kinetics; however, this is probably even too rapid from a practical point of view for its application as supplements. On the other hand, considering the most convenient ratio with the lowest amount of carrier, namely $3 / 1 w / w$, the CD seems to be the best choice, assuring a rapid dissolution of curcumin, in addition to a better morphology of particles produced.

\section{Conclusions}

The SAA process demonstrated to be a very efficient route for the production of polymer-based particles containing CUR. The produced SAA coprecipitated powders showed an increased CUR dissolution rate in an aqueous environment due to the reduction in particle size, as well as the presence of a hydrosoluble carrier; i.e., PVP, dextran, or HP- $\beta$-CD.

Specifically, sub-microparticles were produced for all the investigated systems. Moreover, the influence of the total concentration of solutes on the particles' size and morphology was evaluated. In particular, the increase in this parameter determined the increase in the average diameter of the HP- $\beta$-CD/CUR particles. On the other hand, when the carrier/active ingredient ratio was varied, there was no significant influence on the particle size.

The dissolution tests, conducted under conditions similar to the physiological ones, showed short release times of the antioxidant from the SAA powders, compared to the pure active compound, for all the analyzed systems. However, due to solubility limits, the use of dextran did not allow the increase in the amount of the active ingredient into the composite powders beyond a curcumin/dextran ratio equal to $1 / 6 w / w$. On the contrary, PVP and HP- $\beta-C D$ allowed the production of composite particles with a reduced amount of carrier, up to a ratio curcumin/carrier equal to $1 / 3 w / w$. However, more collapsed particles tended to be produced using PVP. These results are relevant from a nutraceutical/pharmaceutical point of view, allowing the production of supplements with numerous beneficial properties for human health. 
Author Contributions: Conceptualization, I.D.M.; methodology, I.D.M. and P.F.; validation, I.D.M.; formal analysis, P.F.; investigation, P.F.; data curation, P.F.; writing-original draft preparation, I.D.M.; writing-review and editing, I.D.M.; supervision, I.D.M. Both authors have read and agreed to the published version of the manuscript.

Funding: This research received no external funding.

Institutional Review Board Statement: Not applicable.

Informed Consent Statement: Not applicable.

Data Availability Statement: Not applicable.

Acknowledgments: The authors acknowledge Federica Reo for her help in performing the experiments during her Master's Thesis in Food Engineering at the Department of Industrial Engineering of the University of Salerno.

Conflicts of Interest: The authors declare no conflict of interest.

\section{References}

1. Aggarwal, B.B.; Kumar, A.; Bharti, A.C. Anticancer potential of curcumin: Preclinical and clinical studies. J. Anticancer Res. 2003, 23, 363-398.

2. Magro, C.D.; dos Santos, A.E.; Ribas, M.M.; Aguiar, G.P.; Volfe, C.R.; Lopes, M.L.; Siebel, A.M.; Müller, L.G.; Bortoluzzi, A.J.; Lanza, M.; et al. Production of curcumin-resveratrol cocrystal using cocrystallization with supercritical solvent. J. Supercrit. Fluids 2021, 171, 105190. [CrossRef]

3. Avasarala, S.; Zhang, F.; Liu, G.; Wang, R.; London, S.D.; London, L. Curcumin Modulates the Inflammatory Response and Inhibits Subsequent Fibrosis in a Mouse Model of Viral-induced Acute Respiratory Distress Syndrome. PLoS ONE 2013, 8, e57285. [CrossRef] [PubMed]

4. Barnard, D.L.; Kumaki, Y. Recent developments in anti-severe acute respiratory syndrome coronavirus chemotherapy. Future Virol. 2011, 6, 615-631. [CrossRef]

5. Soni, V.K.; Mehta, A.; Ratre, Y.K.; Tiwari, A.K.; Amit, A.; Singh, R.P.; Sonkar, S.C.; Chaturvedi, N.; Shukla, D.; Vishvakarma, N.K. Curcumin, a traditional spice component, can hold the promise against COVID-19? Eur. J. Pharmacol. 2020, 886, 173551. [CrossRef]

6. Zahedipour, F.; Hosseini, S.A.; Sathyapalan, T.; Majeed, M.; Jamialahmadi, T.; Al-Rasadi, K.; Banach, M.; Sahebkar, A. Potential effects of curcumin in the treatment of COVID-19 infection. Phytother. Res. 2020, 34, 2911-2920. [CrossRef] [PubMed]

7. Dourado, D.; Freire, D.T.; Pereira, D.T.; Amaral-Machado, L.; Alencar, N.; de Barros, A.L.B.; Egito, E.S.T. Will curcumin nanosystems be the next promising antiviral alternatives in COVID-19 treatment trials? Biomed. Pharmacother. 2021, 139, 111578. [CrossRef] [PubMed]

8. Saber-Moghaddam, N.; Salari, S.; Hejazi, S.; Amini, M.; Taherzadeh, Z.; Eslami, S.; Rezayat, S.M.; Jaafari, M.R.; Elyasi, S. Oral nano-curcumin formulation efficacy in management of mild to moderate hospitalized coronavirus disease-19 patients: An open label nonrandomized clinical trial. Phytother. Res. 2021, 35, 2616-2623. [CrossRef]

9. Luss, A.; Kulikov, P.P.; Romme, S.B.; Andersen, C.L.; Pennisi, C.P.; Docea, A.O.; Kuskov, A.; Velonia, K.; Mezhuev, Y.O.; Shtilman, M.I.; et al. Nanosized carriers based on amphiphilic poly-N-vinyl-2-pyrrolidone for intranuclear drug delivery. Nanomedicine 2018, 13, 703-715. [CrossRef] [PubMed]

10. Zatorska, M.; Łazarski, G.; Maziarz, U.; Wilkosz, N.; Honda, T.; Yusa, S.-I.; Bednar, J.; Jamróz, D.; Kepczynski, M. Drug-loading capacity of polylactide-based micro- and nanoparticles-Experimental and molecular modeling study. Int. J. Pharm. 2020, 591, 120031. [CrossRef]

11. Di Salle, A.; Viscusi, G.; Di Cristo, F.; Valentino, A.; Gorrasi, G.; Lamberti, E.; Vittoria, V.; Calarco, A.; Peluso, G. Antimicrobial and Antibiofilm Activity of Curcumin-Loaded Electrospun Nanofibers for the Prevention of the Biofilm-Associated Infections. Molecules 2021, 26, 4866. [CrossRef]

12. Hu, Q.; Luo, Y. Chitosan-based nanocarriers for encapsulation and delivery of curcumin: A review. Int. J. Biol. Macromol. 2021, 179, 125-135. [CrossRef]

13. Franco, P.; De Marco, I. Supercritical Antisolvent Process for Pharmaceutical Applications: A Review. Processes 2020, 8, 938. [CrossRef]

14. MacEachern, L.; Kermanshahi-Pour, A.; Mirmehrabi, M. Supercritical Carbon Dioxide for Pharmaceutical Co-Crystal Production. Cryst. Growth Des. 2020, 20, 6226-6244. [CrossRef]

15. Baldino, L.; Cardea, S.; Reverchon, E. Supercritical Assisted Electrospray: An Improved Micronization Process. Polymers 2019, 11, 244. [CrossRef] [PubMed]

16. Tutek, K.; Masek, A.; Kosmalska, A.; Cichosz, S. Application of Fluids in Supercritical Conditions in the Polymer Industry. Polymers 2021, 13, 729. [CrossRef] [PubMed] 
17. Baldino, L.; Cardea, S.; Reverchon, E. Production of antimicrobial membranes loaded with potassium sorbate using a supercritical phase separation process. Innov. Food Sci. Emerg. Technol. 2016, 34, 77-85. [CrossRef]

18. Franco, P.; Belvedere, R.; Pessolano, E.; Liparoti, S.; Pantani, R.; Petrella, A.; De Marco, I. PCL/Mesoglycan Devices Obtained by Supercritical Foaming and Impregnation. Pharmaceutics 2019, 11, 631. [CrossRef] [PubMed]

19. Trucillo, P.; Campardelli, R.; Scognamiglio, M.; Reverchon, E. Control of liposomes diameter at micrometric and nanometric level using a supercritical assisted technique. J. $\mathrm{CO}_{2}$ Util. 2019, 32, 119-127. [CrossRef]

20. Prosapio, V.; De Marco, I.; Reverchon, E. Supercritical antisolvent coprecipitation mechanisms. J. Supercrit. Fluids 2018, 138, 247-258. [CrossRef]

21. Matos, R.L.; Lu, T.; Prosapio, V.; McConville, C.; Leeke, G.; Ingram, A. Coprecipitation of curcumin/PVP with enhanced dissolution properties by the supercritical antisolvent process. J. $\mathrm{CO}_{2}$ Util. 2019, 30, 48-62. [CrossRef]

22. Taki, S.; Badens, E.; Charbit, G. Controlled release system formed by supercritical anti-solvent coprecipitation of a herbicide and a biodegradable polymer. J. Supercrit. Fluids 2001, 21, 61-70. [CrossRef]

23. Di Capua, A.; Adami, R.; Izzo, L.; Reverchon, E. Luteolin/dextran-FITC fluorescent microspheres produced by supercritical assisted atomization. J. Supercrit. Fluids 2017, 130, 97-104. [CrossRef]

24. Wu, H.-T.; Chen, H.-C.; Lee, H.-K. Controlled release of theophylline-chitosan composite particles prepared using supercritical assisted atomization. Braz. J. Chem. Eng. 2019, 36, 895-904. [CrossRef]

25. Adami, R.; Liparoti, S.; Porta, G.D.; Del Gaudio, P.; Reverchon, E. Lincomycin hydrochloride loaded albumin microspheres for controlled drug release, produced by Supercritical Assisted Atomization. J. Supercrit. Fluids 2016, 119, 203-210. [CrossRef]

26. Reverchon, E.; Antonacci, A. Drug-polymer microparticles produced by supercritical assisted atomization. Biotechnol. Bioeng. 2007, 97, 1626-1637. [CrossRef] [PubMed]

27. Prosapio, V.; De Marco, I.; Reverchon, E. PVP/corticosteroid microspheres produced by supercritical antisolvent coprecipitation. Chem. Eng. J. 2016, 292, 264-275. [CrossRef]

28. Montes, A.; Kin, N.; Gordillo, M.; Pereyra, C.; de la Ossa, E.M. Polymer-naproxen precipitation by supercritical antisolvent (SAS) process. J. Supercrit. Fluids 2014, 89, 58-67. [CrossRef]

29. Arango-Ruiz, Á.; Martin, Á.; Cosero, M.J.; Jiménez, C.; Londoño, J. Encapsulation of curcumin using supercritical antisolvent (SAS) technology to improve its stability and solubility in water. Food Chem. 2018, 258, 156-163. [CrossRef]

30. Chhouk, K.; Diono, W.; Kanda, H.; Goto, M. Micronization for Enhancement of Curcumin Dissolution via Electrospraying Technique. Chem. Eng. 2018, 2, 60. [CrossRef]

31. Machmudah, S.; Winardi, S.; Wahyudiono; Kanda, H.; Goto, M. Formation of Fine Particles from Curcumin/PVP by the Supercritical Antisolvent Process with a Coaxial Nozzle. ACS Omega 2020, 5, 6705-6714. [CrossRef]

32. Adami, R.; Di Capua, A.; Reverchon, E. Supercritical Assisted Atomization for the production of curcumin-biopolymer microspheres. Powder Technol. 2016, 305, 455-461. [CrossRef]

33. Huang, Y.; Zu, Y.; Zhao, X.; Wu, M.; Feng, Z.; Deng, Y.; Zu, C.; Wang, L. Preparation of inclusion complex of apigeninhydroxypropyl- $\beta$-cyclodextrin by using supercritical antisolvent process for dissolution and bioavailability enhancement. Int. J. Pharm. 2016, 511, 921-930. [CrossRef] [PubMed]

34. Ndayishimiye, J.; Popat, A.; Kumeria, T.; Blaskovich, M.A.; Falconer, J.R. Supercritical carbon dioxide assisted complexation of benznidazole: $\gamma$-cyclodextrin for improved dissolution. Int. J. Pharm. 2021, 596, 120240. [CrossRef] [PubMed]

35. Palazzo, I.; Campardelli, R.; Scognamiglio, M.; Reverchon, E. Zein/luteolin microparticles formation using a supercritical fluids assisted technique. Powder Technol. 2019, 356, 899-908. [CrossRef]

36. Franco, P.; De Marco, I. Eudragit: A Novel Carrier for Controlled Drug Delivery in Supercritical Antisolvent Coprecipitation. Polymers 2020, 12, 234. [CrossRef] [PubMed]

37. Tabernero, A.; Cardea, S. Supercritical carbon dioxide techniques for processing microbial exopolysaccharides used in biomedical applications. Mater. Sci. Eng. C 2020, 112, 110940. [CrossRef] [PubMed]

38. Zahran, F.; Cabañas, A.; Cheda, J.A.; Renuncio, J.A.; Pando, C. Dissolution rate enhancement of the anti-inflammatory drug diflunisal by coprecipitation with a biocompatible polymer using carbon dioxide as a supercritical fluid antisolvent. J. Supercrit. Fluids 2014, 88, 56-65. [CrossRef]

39. Yan, T.; Ji, M.; Sun, Y.; Zhao, J.; Zhang, H.; Wang, Z. Preparation and characterization of baicalein/hydroxypropyl- $\beta$-cyclodextrin inclusion complex for enhancement of solubility, antioxidant activity and antibacterial activity using supercritical antisolvent technology. J. Incl. Phenom. Macrocycl. Chem. 2019, 96, 285-295. [CrossRef]

40. Pan, Y.-J.; Xu, P.-Y.; Chen, B.-Q.; Fu, C.-P.; Kankala, R.K.; Chen, A.-Z.; Wang, S.-B. Supercritical antisolvent process-assisted fabrication of chrysin-polyvinylpyrrolidone sub-microparticles for improved anticancer efficiency. J. Supercrit. Fluids 2020, 162, 104847. [CrossRef]

41. Franco, P.; De Marco, I. Preparation of non-steroidal anti-inflammatory drug/ $\beta$-cyclodextrin inclusion complexes by supercritical antisolvent process. J. $\mathrm{CO}_{2}$ Util. 2020, 44, 101397. [CrossRef]

42. Rosas, M.D.; Piqueras, C.M.; Piva, G.K.; Ramírez-Rigo, M.V.; Filho, L.C.; Bucalá, V. Simultaneous formation of inclusion complex and microparticles containing Albendazole and $\beta$-Cyclodextrin by supercritical antisolvent co-precipitation. J. CO 2 Util. 2021, 47, 101505. [CrossRef] 
43. Sahu, A.; Bora, U.; Kasoju, N.; Goswami, P. Synthesis of novel biodegradable and self-assembling methoxy poly(ethylene glycol)-palmitate nanocarrier for curcumin delivery to cancer cells. Acta Biomater. 2008, 4, 1752-1761. [CrossRef] [PubMed]

44. Rezaei, A.; Nasirpour, A. Evaluation of Release Kinetics and Mechanisms of Curcumin and Curcumin- $\beta$-Cyclodextrin Inclusion Complex Incorporated in Electrospun Almond Gum/PVA Nanofibers in Simulated Saliva and Simulated Gastrointestinal Conditions. BioNanoScience 2019, 9, 438-445. [CrossRef]

45. Abdurrahmanoglu, S.; Firat, Y. Synthesis and characterization of new dextran-acrylamide gels. J. Appl. Polym. Sci. 2007, 106, 3565-3570. [CrossRef]

46. Di Capua, A.; Bejarano, A.; Adami, R.; Reverchon, E. Preparation and characterization of Chilean propolis coprecipitates using Supercritical Assisted Atomization. Chem. Eng. Res. Des. 2018, 136, 776-785. [CrossRef]

47. Ismail, E.H.; Sabry, D.Y.; Mahdy, H.; Khalil, M.M.H. Synthesis and Characterization of some Ternary Metal Complexes of Curcumin with 1,10-phenanthroline and their Anticancer Applications. J. Sci. Res. 2014, 6, 509-519. [CrossRef]

48. Yin, H.; Wang, C.; Yue, J.; Deng, Y.; Jiao, S.; Zhao, Y.; Zhou, J.; Cao, T. Optimization and characterization of 1,8cineole/hydroxypropyl- $\beta$-cyclodextrin inclusion complex and study of its release kinetics. Food Hydrocoll. $2020,110$. [CrossRef] 